\title{
Comparative Evaluation of the Effects of Antimicrobial Photodynamic Therapy With an LED and a Laser on the Proliferation of Human Gingival Fibroblasts on the Root Surface: An In Vitro Study
}

\author{
Mahsa Koochaki $^{\circledR}$, Amirreza Hendi $^{\circledR}$, Mahmood Ghasemi ${ }^{\circledR}$, Ehsan Seyedjafari ${ }^{\circledR}{ }^{\circledR}$ Mehdi $^{\circledR}$ \\ Hamidain $^{5^{\circledR}}$, Nasim Chiniforush ${ }^{6 * \mathbb{(}}$ \\ 'Department of Oral and Maxillofacial Disease, School of Dentistry, Tehran University of Medical Sciences, \\ Tehran, Iran \\ ${ }^{2}$ Dental Sciences Research Center, Department of Prosthodontics, School of Dentistry, Guilan University of \\ Medical Sciences, Rasht, Iran \\ ${ }^{3}$ Department of periodontics, Dental Faculty, Tehran Medical Sciences, Islamic Azad University, Tehran, Iran \\ ${ }^{4}$ Department of Biotechnology, College of Sciences, University of Tehran, Tehran, Iran \\ ${ }^{5}$ Dental Faculty, Tehran Medical Sciences, Islamic Azad University, Tehran, Iran \\ ${ }^{6}$ Laser Research Center of Dentistry, Dentistry Research Institute, Tehran University of Medical Sciences, Tehran, Iran
}

\section{*Correspondence to \\ Nasim Chiniforush, \\ DDS, PhD; Assistant Professor, Laser Research Center of Dentistry, Dentistry Research Institute, Tehran University of Medical Sciences, Tehran, Iran. Tel/ Fax: +982183384304 Email: n-chiniforush@sina.tums. ac.ir}

Received: September 20, 2020 Accepted: March 14, 2021 Published online August 30, 2021

\begin{abstract}
Introduction: This study aimed to compare the effects of root biomodification by citric acid and antimicrobial photodynamic therapy (aPDT) with LED and laser on the proliferation of human gingival fibroblasts (HGFs).

Methods: This in vitro experimental study evaluated 60 single-rooted teeth extracted due to periodontal disease. The teeth underwent scaling and root planing (SRP), and then $5 \times 5 \mathrm{~mm}$ blocks were prepared from the cervical area of the teeth $1 \mathrm{~mm}$ apical to the cementoenamel junction. The blocks were divided into 4 groups ( $n=15$ blocks): SRP alone (control), SRP + citric acid, SRP + toluidine blue (TBO) + LED light, and SRP + TBO + laser. HGFs were seeded on the surface of the samples, and the methyl thiazolyl tetrazolium (MTT) assay was performed after 24, 48 and 72 hours. Group comparisons were performed using repeated measures ANOVA, while pairwise comparisons of the time points were performed by an LSD test.

Results: Cell proliferation was higher in all experimental groups at 48 and 72 hours, compared with 24 hours $(P<0.05)$. Cell proliferation was significantly different in the citric acid group at 24 hours $(P=0.016)$ and 48 hours $(P=0.015)$, compared with other groups. However, cell proliferation was not significantly different in the aPDT group with LED Photosan and a diode laser at 24 and 48 hours $(P>0.05)$.

Conclusion: aPDT and citric acid can enhance the proliferation of HGFs on dentin blocks. Further studies can pave the way for their future use in the clinical setting.

Keywords: Antimicrobial photodynamic therapy; Laser; LED; Human gingival fibroblasts; Citric acid.
\end{abstract}

\section{Introduction}

Periodontal disease is highly prevalent among adults, affecting $90 \%$ of the world's population. ${ }^{1}$ Periodontitis is an inflammatory disease of the tooth-supporting structures, which is caused by bacterial infection. If left untreated, it can eventually lead to tooth loss. ${ }^{2}$

Scaling and root planing (SRP) is the gold standard for the treatment of periodontitis. ${ }^{3}$ Although significant improvements have been reported in periodontal status following SRP, the complete elimination of subgingival periodontal pathogens and irritants is not always possible. ${ }^{4}$ SRP has some physical limitations as well, such as difficulty in accessing deep periodontal pockets, root concavities and furcation areas, which can compromise the complete elimination of calculus and bacterial debris from deep periodontal pockets. ${ }^{5-7}$ To overcome the limitations of SRP and minimize the bacterial load, several pharmacological adjuncts are also used to improve the treatment efficacy. ${ }^{3}$ Locally-delivered antibiotics are an acceptable adjunct for this purpose and are less likely to cause systemic complications. ${ }^{8}$ However, problems related to the emergence of drug resistance with the widespread use of antibiotics (local and systemic) and poor efficacy of medications against biofilms have led to 
the popularity of antimicrobial photodynamic therapy (aPDT) for the management of periodontitis. ${ }^{2,4}$ Root surface alterations caused by periodontal disease can impair wound healing by connective tissue formation or periodontal regeneration. ${ }^{9}$ Root conditioning agents such as citric acid, ${ }^{10}$ high-power lasers, ${ }^{11}$ and aPDT have been applied to improve periodontal tissue attachment to the root surfaces. ${ }^{12}$

The principles of aPDT involve the use of a nontoxic light-sensitive dye called a "photosensitizer" (PS) combined with irradiation of a harmless visible light (low energy). ${ }^{13}$ Typically, the light must be of a specific wavelength, ${ }^{14}$ but even broad-spectrum light can activate PSs such as toluidine blue (TBO). Upon the administration of the PS in the periodontal pocket and excitation with light, it undergoes a transition from a ground single state to a higher-energy triplet state that reacts with endogenous oxygen to produce singlet oxygen and other radical species, causing rapid and selective destruction of target bacterial species. ${ }^{1,8}$ The main advantages of aPDT over the conventional antimicrobial therapies include the immediate onset of action, elimination of resistant microorganisms and secreted virulence factors, local delivery of PS, and double selectivity (deleterious effect only on sites where both PS and light are delivered concomitantly). ${ }^{2}$

Various acidic products were tested for hard tissue demineralization without side effects. The best results were obtained with citric acid at a $\mathrm{pH}$ of 1 for 3 minutes. ${ }^{15}$ A previous in vitro study demonstrated that demineralization/biomodification of root surfaces by aPDT did not impair the proliferation of human gingival fibroblasts (HGFs), ${ }^{12}$ and stimulated the viability of oral fibroblasts ${ }^{15}$ and osteoblasts. ${ }^{16}$ To our knowledge, no study has evaluated the effect of aPDT activated by an LED and a laser with the same wavelength on the proliferation of HGFs.

The aim of this study was to compare the effects of root biomodification with citric acid and aPDT with TBO and LED or laser on the proliferation of HGFs.

\section{Materials and Methods}

This in vitro experimental study evaluated 60 singlerooted teeth extracted due to periodontal disease. The sample size was calculated to be 15 in each of the four groups assuming $\alpha=0.05, \beta=0.2$, mean standard deviation of the proliferation index to be 0.79 , and effect size of 0.88 , using PASS 11 Multivariate Comparison software. All teeth underwent ultrasonic SRP with Gracey curettes (Hu-Friedy, Chicago, USA). Next, $5 \times 5 \mathrm{~mm}$ tooth blocks were prepared from the proximal surfaces of the teeth $1 \mathrm{~mm}$ apical to the cementoenamel junction.

Dental blocks were randomly divided into 4 groups $(n=15)$, and the PS was activated based on its standard wavelength as follows:
1. SRP alone (control): Dental blocks were treated by SRP alone.

2. SRP + citric acid: Dental blocks were treated with citric acid $(\mathrm{pH}=1)$ burnished for 1 minute following SRP.

3. SRP + TBO + LED: After SRP, dental blocks were treated with $0.1 \mathrm{mg} / \mathrm{mL}$ TBO (Blue ${ }^{+\mathrm{T}}$, Novateb, Iran) for 5 minutes in the dark at $37^{\circ} \mathrm{C}$ and were then irradiated with $630 \pm 10 \mathrm{~nm}$ LED (Photosan system,DK-2800; CMS Dental, Copenhagen, Denmark) with an output power of 2000-4000 $\mathrm{mW} / \mathrm{cm}^{2}$ in a continuous-wave mode for 30 seconds from a $1 \mathrm{~cm}$ distance with $17.18 \mathrm{~J} / \mathrm{cm}^{2}$ energy density. TBO was used as PS in this group.

4. SRP + TBO + laser: After SRP, dental blocks were treated with $0.1 \mathrm{mg} / \mathrm{mL}$ TBO for 5 minutes in the dark at $37^{\circ} \mathrm{C}$ and were then irradiated with a 635 $\mathrm{nm}$ diode laser (Konfteck, Taiwan) with an output power of $220 \mathrm{~mW}$ in a continuous-wave mode with an energy density of $11.8 \mathrm{~J} / \mathrm{cm}^{2}$ for 30 seconds with $7 \mathrm{~mm}$ tip diameter from a $1 \mathrm{~cm}$ distance.

For cell culture, the HGF cell line was purchased from the Pasteur Institute Cell Bank (Tehran, Iran). The cells were cultivated in the conventional Dulbecco's modified Eagle's medium supplemented with $10 \%$ fetal bovine serum. Before cell culture, the samples were sterilized by immersion in $70 \%$ ethanol for 24 hours. To ensure the absence of microbial contamination, the samples were incubated in the whole medium in 24-well culture plates for 24 hours and were then examined under a light microscope. HGFs were then detached from the culture flask by trypsin and seeded on the surface of the samples at a density of $10^{4}$ cells/samples. The plates were incubated at $37^{\circ} \mathrm{C}$ with $5 \% \mathrm{CO}_{2}$ for 24,48 and 72 hours.

Cell proliferation was assessed by the methyl thiazolyl tetrazolium (MTT) assay after 24, 48 and 72 hours. HGFs were treated with the MTT reagent for 4 hours at $37^{\circ} \mathrm{C}$ $(10 \% \mathrm{v} / \mathrm{v}$ of the medium). The MTT assay measures the mitochondrial activity of the cells by assessing the conversion of water-soluble 3-(4,5-dimethylthiazol-2-yl)2,5-diphenyltetrazolium bromide to insoluble formazan crystals. The crystals are then dissolved in $100 \mu \mathrm{L}$ dimethyl sulfoxide, and the optical density of the resultant solution is read by an ELISA Reader at a wavelength of $570 \mathrm{~nm}$ (Anthos 2020, Austria).

\section{Statistical Analysis}

Data were analyzed by SPSS version 22. The normal distribution of data was evaluated using the KolmogorovSmirnov test. Group comparisons were performed using repeated measures ANOVA, and pairwise comparisons of the time points were carried out by LSD test. $P<0.05$ was considered statistically significant. 


\section{Results}

In this study, 60 dental blocks measuring $5 \times 5 \mathrm{~mm}$ were evaluated in 4 treatment groups and at 3 time points of 24, 48 and 72 hours. Table 1 presents the results of the MTT assay at different time points. The KolmogorovSmirnov test confirmed the normal distribution of the data $(P \geq 0.05)$.

Cell proliferation was higher in all experimental groups at 48 and 72 hours compared with 24 hours $(P<0.05)$. The citric acid group had significant differences from other groups in terms of higher cell proliferation at 24 hours $(P=0.016)$ and 48 hours $(P=0.009)$ (Figure 1). However, cell proliferation in the aPDT with LED and diode laser group was not significantly different at 24 and 48 hours $(\mathrm{P}>0.05)$. Cell proliferation in the citric acid group at 72 hours was higher than that in the control and aPDT groups, but not significantly $(P=0.304)$ (Table 2$)$.

Table 1. Multiple Comparisons of Cell Proliferation Within Groups at Different Time Points

\begin{tabular}{|c|c|c|c|c|}
\hline \multirow{2}{*}{ Treatment groups } & \multirow{2}{*}{ Time } & \multirow{2}{*}{$P$ Value } & \multicolumn{2}{|c|}{ 95\% Confidence Interval } \\
\hline & & & Lower Bond & Upper Bound \\
\hline \multirow{2}{*}{ Control (SRP) $24 \mathrm{~h}$} & $48 \mathrm{~h}$ & 0.449 & -0.041 & 0.015 \\
\hline & $72 \mathrm{~h}$ & 0.000 & -0.236 & -0.079 \\
\hline Control (SRP) $48 \mathrm{~h}$ & $72 \mathrm{~h}$ & 0.000 & -0.273 & -0.115 \\
\hline \multirow{2}{*}{$C A+S R P 24 h$} & $48 \mathrm{~h}$ & 0.224 & -0.305 & 0.062 \\
\hline & $72 \mathrm{~h}$ & 0.055 & -0.364 & 0.003 \\
\hline$C A+S R P 48 h$ & $72 \mathrm{~h}$ & 0.679 & -0.242 & 0.125 \\
\hline \multirow{2}{*}{ SRP + LED $24 \mathrm{~h}$} & $48 \mathrm{~h}$ & 0.303 & -0.228 & 0.060 \\
\hline & $72 \mathrm{~h}$ & 0.02 & -0.316 & -0.028 \\
\hline $\mathrm{SRP}+\mathrm{LED} 48 \mathrm{~h}$ & $72 \mathrm{~h}$ & 0.268 & -0.232 & 0.055 \\
\hline \multirow{2}{*}{ SRP + LASER $24 \mathrm{~h}$} & $48 \mathrm{~h}$ & 0.893 & -0.195 & 0.138 \\
\hline & $72 \mathrm{~h}$ & 0.038 & -0.344 & -0.10 \\
\hline SRP + LASER $48 \mathrm{~h}$ & $72 \mathrm{~h}$ & 0.083 & -0.316 & 0.018 \\
\hline
\end{tabular}

SRP, Scaling and root planing; CA, Citric acid.

Table 2. Multiple Comparisons of Cell Proliferation Between Study Groups at Different Time Points

\begin{tabular}{|c|c|c|c|c|c|}
\hline \multirow{2}{*}{ Time } & \multirow{2}{*}{\multicolumn{2}{|c|}{ Treatment Groups }} & \multirow{2}{*}{$P$ Value } & \multicolumn{2}{|c|}{$95 \%$ Confidence Interval } \\
\hline & & & & Lower bond & Upper Bound \\
\hline \multirow{6}{*}{$24 \mathrm{~h}$} & \multirow{3}{*}{ Control (SRP) } & $\mathrm{CA}+\mathrm{SRP}$ & 0.016 & -0.178 & -0.016 \\
\hline & & SRP + LED & 0.624 & -0.115 & 0.046 \\
\hline & & SRP + LASER & 0.228 & -0.137 & 0.024 \\
\hline & \multirow{2}{*}{$\mathrm{CA}+\mathrm{SRP}$} & $\mathrm{SRP}+\mathrm{LED}$ & 0.158 & -0.017 & 0.144 \\
\hline & & SRP + LASER & 0.491 & -0.040 & 0.122 \\
\hline & SRP + LED & SRP + LASER & 0.861 & -0.103 & 0.058 \\
\hline \multirow{6}{*}{$48 \mathrm{~h}$} & \multirow{3}{*}{ Control (SRP) } & $\mathrm{CA}+\mathrm{SRP}$ & 0.009 & -0.452 & 0.050 \\
\hline & & SRP + LED & 0.148 & -0.351 & 0.04 \\
\hline & & SRP + LASER & 0.317 & -0.318 & 0.074 \\
\hline & \multirow{2}{*}{$\mathrm{CA}+\mathrm{SRP}$} & $S R P+L E D$ & 0.479 & -0.095 & 0.296 \\
\hline & & SRP + LASER & 0.247 & -0.062 & 0.330 \\
\hline & SRP + LED & SRP + LASER & 0.962 & -0.163 & 0.229 \\
\hline \multirow{6}{*}{$72 \mathrm{~h}$} & \multirow{3}{*}{ Control (SRP) } & $\mathrm{CA}+\mathrm{SRP}$ & 0.253 & -0.297 & 0.057 \\
\hline & & SRP + LED & 0.855 & -0.227 & 0.128 \\
\hline & & SRP + LASER & 0.617 & -0.254 & 0.101 \\
\hline & \multirow{2}{*}{$\mathrm{CA}+\mathrm{SRP}$} & $S R P+L E D$ & 0.671 & -0.106 & 0.248 \\
\hline & & SRP + LASER & 0.893 & -0.133 & 0.221 \\
\hline & SRP + LED & SRP + LASER & 0.972 & -0.204 & 0.150 \\
\hline
\end{tabular}

SRP, Scaling and root planing; CA, Citric acid. 


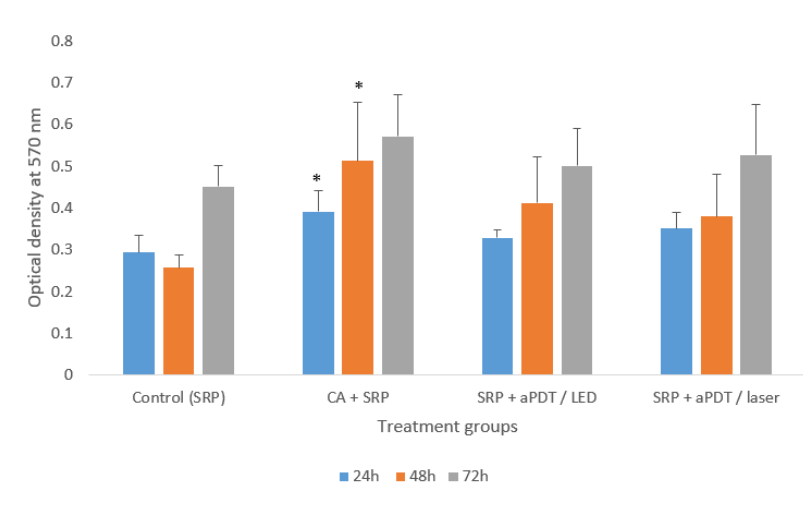

Figure 1. Comparison of Cell Proliferation Among the Study Groups. The error bars indicate the standard deviation of the samples. *Significantly different from the control (SRP) group, $P<0.05$.

\section{Discussion}

The present study demonstrated that the proliferation of HGFs was not impaired by root surface modification with mechanical, chemical and photodynamic treatments. It is important to clarify that all these treatments have been shown to induce a reduction in bacterial proliferation, leading to their eventual death. ${ }^{17-19}$

HGFs were selected for this study because the connective tissue and collagen fibers have the first contact with dentin during the healing process after periodontal surgery. ${ }^{15}$ Chemical treatments may increase the stability of the blood clot in the early stages of periodontal repair and enhance the adhesion of blood cells and fibrin. Basically, any adherent cell line may be acclimated to test the biocompatibility of the root fragment surface. If a surface is not a good environment for cells, no adhesion and proliferation occur. A concerted effort has been made in the field of root biomodification to improve the outcome of periodontal therapy by favoring the attachment of the regenerated periodontal structures to the root surface.

In the present study, treatment with citric acid increased the proliferation of HGFs compared with the control group for up to 48 hours. However, there was no significant difference between the groups at 72 hours. The reason for this finding can be the residual chemical agents (citric acid and PS) that may interfere with cell proliferation, and it is likely that the cells in all groups reach a confluence point within 72 hours.

Leite et $\mathrm{al}^{20}$ in an in vitro study evaluated blood clot formation utilizing a drop of human blood over the treated root fragments, and they reported that groups treated with citric acid promoted a surface capable of maintaining a dense fibrin network filled with blood elements (an ideal blood clot). However, groups treated by SRP did not induce blood clot formation, and only a moderate and scarce fibrin network formed. The idea of adding the aPDT group to the present study arose from the results of previous studies. ${ }^{9,12}$ Pessoa et $\mathrm{al}^{21}$ in their case report demonstrated that the use of $10 \mathrm{mg} / \mathrm{mL}$ TBO caused clinical signs of enamel demineralization and symptoms of hypersensitivity. But later, Damante et $\mathrm{al}^{12}$ demonstrated that $100 \mu \mathrm{g} / \mathrm{mL}$ TBO caused a significant loss of dentin microhardness and surface wear of $9.06 \pm 7.69 \mu \mathrm{m}$ and could be as effective as citric acid conditioning to stimulate cell adhesion and proliferation. We did also use the same concentration of TBO in our study, which stimulated the proliferation of HGFs.

The findings of the present study also confirmed the previous findings regarding the toxicity of TBO and possibly other PSs such as methylene blue and indocyanine green for bacteria and their safety for cells. ${ }^{22}$ In a histological study, no inflammation in the tissue following TBO exposure was shown. ${ }^{23}$

Karam et $\mathrm{al}^{15}$ showed that a cell culture medium, conditioned for $24 \mathrm{~h}$ by root fragments treated with aPDT with $100 \mu \mathrm{g} / \mathrm{mL}$ TBO, promoted an increase in the proliferation of HGFs after 48 and 72 hours. They also suggested that some ions, such as calcium, could be released into the medium. Calcium induces a multitude of biological processes and activation of signaling pathways in cells that could lead to higher cell proliferation. ${ }^{24}$ Karam et $\mathrm{al}^{15}$ showed that gingival fibroblasts seeded over root fragments treated with aPDT, citric acid plus tetracycline, and SRP had similar growth rates in all groups, which was in accordance with the present findings. We may suggest that changes in surface topography caused by demineralization may favor cell proliferation. It is worth mentioning that the dye causes demineralization, rather than the photodynamic reaction. The $\mathrm{pH}$ of a dye solution may vary based on the solvent and its concentration. We did not measure the $\mathrm{pH}$ of the dye before or during irradiation, which is a limitation of our study. However, other studies used the same concentration of TBO and mentioned the $\mathrm{pH}$ to be $4 .^{9}$ Another point is that the pre-irradiation time used in aPDT may contribute to the demineralizing effect such that the higher the preirradiation time, the greater the demineralization effect would be. ${ }^{12}$

In the clinical setting, the use of aPDT as an adjunct to periodontal treatment may show different results. Martins et $\mathrm{al}^{7}$ stated that a single episode of aPDT significantly improved clinical periodontal parameters and more effectively eliminated the periodontal pathogens of the red complex. Akram et $\mathrm{al}^{3}$ in their systematic review and meta-analysis assessed the quality of evidence on the efficacy of aPDT and laser irradiation as an adjunct to open flap debridement and stated that only aPDT as an adjunct to flap debridement showed superior results with regard to clinical periodontal parameters compared with flap debridement alone in the treatment of chronic periodontitis. On the other hand, Chambrone et $\mathrm{al}^{13}$ concluded that aPDT may result in comparable clinical improvements in pocket depth and clinical attachment 
level when compared with the conventional periodontal therapy for both periodontitis and peri-implantitis.

Sperandio et $\mathrm{al}^{25}$ found that laser radiation at a wavelength of $660 \mathrm{~nm}$ with the power of $100 \mathrm{~mW}$ and energy density of $117.85 \mathrm{~J} / \mathrm{cm}^{2}$ had beneficial effects on accelerating the recovery process. The premise of both aPDT and laser irradiation in the treatment of chronic periodontitis is that aPDT involves the activation of the dye molecule from the inactive singlet state to the excited triplet state that reacts with endogenous oxygen to produce fatal reactive species that facilitate bacterial cell death. On the other hand, laser irradiation involves the insertion of the laser probe into the periodontal pocket to produce space and exert anti-infective (against perio-pathogens) and bio-stimulatory effects on the surrounding periodontal tissues.

The results of the current study indicated that aPDT and also citric acid treatment as an adjunct to periodontal therapy did not have any adverse effects on the proliferation of HGFs according to the MTT assay. A study by Kömerik et $\mathrm{a}^{26}$ showed no adverse effects such as ulceration of the epithelium or inflammation of the connective tissue of rats after aPDT even with the highest light doses and $\mathrm{TBO}$ concentrations.

\section{Conclusion}

aPDT with TBO activated by an LED and a laser and citric acid treatment as an adjunct to periodontal therapy can enhance the proliferation of HGFs on dentin blocks.

\section{Ethical Considerations}

This study was in-vitro.

Conflict of Interests

The authors declare that they have no conflict of interest.

\section{Acknowledgment}

This study was supported by Tehran university Medical Sciences and Islamic Azad University.

\section{Reference}

1. Akram Z, Al-Shareef SA, Daood U, Asiri FY, Shah AH, AlQahtani MA, et al. Bactericidal efficacy of photodynamic therapy against periodontal pathogens in periodontal disease: a systematic review. Photomed Laser Surg. 2016;34(4):137-49. doi: 10.1089/pho.2015.4076.

2. De Freitas LM, Calixto GM, Chorilli M, Giusti JS, Bagnato VS, Soukos NS, et al. Polymeric nanoparticle-based photodynamic therapy for chronic periodontitis in vivo. Int J Mol Sci. 2016;17(5):769. doi: 10.3390/ijms17050769.

3. Akram Z, Shafqat SS, Niaz MO, Raza A, Naseem M. Clinical efficacy of photodynamic therapy and laser irradiation as an adjunct to open flap debridement in the treatment of chronic periodontitis: a systematic review and meta-analysis. Photodermatol Photoimmunol Photomed. 2020;36(1):3-13. doi: 10.1111/phpp.12499.

4. Joseph B, Janam P, Narayanan S, Anil S. Is antimicrobial photodynamic therapy effective as an adjunct to scaling and root planing in patients with chronic periodontitis? A systematic review. Biomolecules. 2017;7(4):79. doi: 10.3390/ biom7040079.

5. Nagarakanti S, Gunupati S, Chava VK, Reddy BV Effectiveness of subgingival irrigation as an adjunct to scaling and root planing in the treatment of chronic periodontitis: a systematic review. J Clin Diagn Res. 2015;9(7):ZE06. doi: 10.7860/JCDR/2015/13862.6210.

6. Rabbani GM, Ash MM, Caffesse RG. The effectiveness of subgingival scaling and root planing in calculus removal. J Periodontol. 1981;52(3):119-23. doi: 10.1902/ jop.1981.52.3.119.

7. Martins SH, Novaes Jr AB, Taba Jr M, Palioto DB, Messora $\mathrm{MR}$, Reino DM, et al. Effect of surgical periodontal treatment associated to antimicrobial photodynamic therapy on chronic periodontitis: A randomized controlled clinical trial. J Clin Periodontol. 2017;44(7):717-28. doi: 10.1111/jcpe.12744.

8. Azarpazhooh A, Shah PS, Tenenbaum HC, Goldberg MB. The effect of photodynamic therapy for periodontitis: A systematic review and meta-analysis. J Periodontol. 2010;81(1):4-14. doi: 10.1902/jop.2009.090285.

9. Ferreira R, de Toledo Barros RT, Karam PS, Sant'Ana AC, Greghi SL, de Rezende ML, et al . Comparison of the effect of root surface modification with citric acid, EDTA, and aPDT on adhesion and proliferation of human gingival fibroblasts and osteoblasts: an in vitro study. Lasers Med Sci. 2018;33(3):533-8. doi: 10.1007/s10103-017-2395-3.

10. Register AA, Burdick FA. Accelerated reattachment with cementogenesis to dentin, demineralized in situ: I. Optimum range. J Periodontol. 1975;46(11):646-55. doi: 10.1902/jop.1975.46.11.646.

11. Qadri T, Javed F, Poddani P, Tunér J, Gustafsson A. Longterm effects of a single application of a water-cooled pulsed Nd: YAG laser in supplement to scaling and root planing in patients with periodontal inflammation. Lasers Med Sci. 2011;26(6):763-6. doi: 10.1007/s10103-010-0807-8.

12. Damante CA, Ducati P, Ferreira R, Salmeron S, Zangrando MS, de Rezende ML, et al. In vitro evaluation of adhesion/ proliferation of human gingival fibroblasts on demineralized root surfaces by toluidine blue $\mathrm{O}$ in antimicrobial photodynamic therapy. Photodiagnosis Photodyn Ther. 2016;13:303-7. doi: 10.1016/j.pdpdt.2015.08.009.

13. Chambrone L, Wang HL, Romanos GE. Antimicrobial photodynamic therapy for the treatment of periodontitis and peri-implantitis: An American Academy of Periodontology best evidence review. J Periodontol. 2018;89(7):783-803. doi: 10.1902/jop.2017.170172.

14. Niedre MJ, Yu CS, Patterson MS, Wilson BC. Singlet oxygen luminescence as an in vivo photodynamic therapy dose metric: validation in normal mouse skin with topical amino-levulinic acid. Br J Cancer. 2005;92(2):298-304. doi: 10.1038/sj.bjc.6602331.

15. Karam PS, Ferreira R, Oliveira RC, Greghi SL, de Rezende ML, Sant'Ana AC,et al. Stimulation of human gingival fibroblasts viability and growth by roots treated with high intensity lasers, photodynamic therapy and citric acid. Arch Oral Biol. 2017;81:1-6. doi: 10.1016/j. archoralbio.2017.04.012. 
16. Damante CA, Karam PS, Ferreira R, Rezende ML, Greghi SL, Sant'Ana AC, Zangrando MS. Root surface demineralization by citric acid/tetracycline gel and aPDT associated to subepithelial connective tissue graft improves root coverage outcomes. A 12-month preliminary randomized clinical trial. J Photochem Photobiol B. 2019 Aug 1;197:111528. doi: 10.1016/j.jphotobiol.2019.111528.

17. Daly CG. Anti-bacterial effect of citric acid treatment of periodontally diseased root surfaces in vitro. J Clin Periodontol. 1982;9(5):386-92. doi: 10.1111/j.1600051X.1982.tb02049.x.

18. Salmeron S, Rezende ML, Consolaro A, Sant'Ana AC, Damante CA, Greghi SL, et al. Laser therapy as an effective method for implant surface decontamination: a histomorphometric study in rats. J Periodontol. 2013;84(5):641-9. doi: 10.1902/jop.2012.120166.

19. de Carvalho Goulart R, Thedei Jr G, Souza SL, Tedesco AC, Ciancaglini P. Comparative study of methylene blue and erythrosine dyes employed in photodynamic therapy for inactivation of planktonic and biofilm-cultivated Aggregatibacter actinomycetemcomitans. Photomed Laser Surg. 2010;28(S1):S-85. doi: 10.1089/pho.2009.2698.

20. Leite FR, Sampaio JE, Zandim DL, Dantas AA, Leite ER, Leite AA. Influence of root-surface conditioning with acid and chelating agents on clot stabilization. Quintessence Int. 2010;41(4): 341-9.
21. Pessoa L, Galvão V, Damante C, Sant’Ana AC. Removal of black stains from teeth by photodynamic therapy: clinical and microbiological analysis. BMJ Case Reports. 2015;2015:bcr2015212276. doi: 10.1136/bcr-2015-212276.

22. Maisch T. Anti-microbial photodynamic therapy: useful in the future?. Lasers Med Sci. 2007;22(2):83-91. doi: 10.1007/ s10103-006-0409-7.

23. Margaron P, Sorrenti R, Levy JG. Photodynamic therapy inhibits cell adhesion without altering integrin expression. BBA-Mol Cell Res. 1997 ;1359(3):200-10. doi: 10.1016/ S0167-4889(97)00115-8.

24. Decrock E, Hoorelbeke D, Ramadan R, Delvaeye T, De Bock M, Wang N, et al. Calcium, oxidative stress and connexin channels, a harmonious orchestra directing the response to radiotherapy treatment?. BBA-Mol Cell Res. 2017;1864(6):1099-120. doi: 10.1016/j.bbamcr.2017.02.007.

25. Sperandio FF, Simoes A, Aranha AC, Corrêa L, Orsini Machado de Sousa SC. Photodynamic therapy mediated by methylene blue dye in wound healing. Photomed Laser Surg. 2010;28(5):581-7. doi: 10.1089/pho.2009.2601.

26. Kömerik NU, Nakanishi H, MacRobert AJ, Henderson B, Speight P, Wilson M. In vivo killing of Porphyromonas gingivalis by toluidine blue-mediated photosensitization in an animal model. Antimicrob Agents Chemother. 2003;47(3):932-40. doi:10.1128/AAC.47.3.932-940.2003. 